\title{
Çift Taraflı Diz Protezi Sonrası Ortaya Çıkan Komplikasyonlar
}

\section{Complications Appearing After Bilateral Knee Arthroplasty}

\author{
Özgür Korkmaz, Mehmet Akif Kaygusuz*, Melih Malkoç \\ Or-Ahayim Özel Balat Hastanesi, Ortopedi ve Travmatoloji, Istanbul, Türkiye \\ *Metin Sabancı Baltalimanı Kemik Hastalıkları Eğitim ve Araştırma Hastanesi, Ortopedi ve Travmatoloji, istanbul, Türkiye
}

\section{Özet}

Total endo diz protezleri ortopedik cerrahideki en etkili tedavi yöntemlerinden biridir. Çeşitli komplikasyonlar bu cerrahi uygulamada görülebilir. Enfeksiyon, periprostatik kırık, diz çıkığı, patellar tendon rüptürü ve nörovasküler yaralanmalar komplikasyonlardan bazılarıdır. Olgumuza, dış merkezde aynı seansta bilateral diz protezi uygulaması yapılmış. Erken dönem sağ femur suprakondiler kırığı oluşması üzerine açık redüksiyon internal fiksasyon yapılmış. Sonrasında sağ dizde periprostatik kırık ve sol dizde de insörtün çıkmasına bağlı diz çıkığı oluşmuş. Periprostatik kırıkolan dize açık redüksiyon internal fiksasyon, insert çıkığı olan dize diz protezi revizyonu ameliyatları yapıldı. Bu vaka bildiriminde amacımız diz protezi cerrahisi sonucu ortaya çıkabilecek komplikasyonları bildirmek ve tedavi yöntemlerini tartışmaktır. (Haseki Tıp Bülteni 2013; 51: 28-30)

Anahtar Kelimeler: Diz protezi, diz çıkı̆ı, periprostatik kırık

\begin{abstract}
Total knee arthroplasty is one of the most effective surgical treatment modalities among orthopedic procedures. Several complications including infection, periprostatic fracture, knee dislocation, patellar tendon ruptures, neurovascular injuries may happen after surgery. In our case, bilateral knee arthroplasty had been performed during the same session in another center. Open reduction and internal fixation had been performed due to a supracondylar femur fracture in the right knee occurred in the early post-operative period. After a period, a fracture in the right knee and knee dislocation in the left knee had occurred. We performed an open reduction internal fixation for the right knee and knee arthroplasty revision for left knee. In this case report, our aim was to inform and discuss the treatment options for the complications that may occur as a result of knee replacement surgery. (The Medical Bulletin of Haseki 2013; 51: 28-30)
\end{abstract}

Key Words: Knee arthroplasty, knee dislocation, periprosthetic fracture

\section{Giriş}

Yaşlı hasta grubunda osteoartrit fonksiyonel kısıtlıığın ve hareket kaybının en sık nedenidir $(1,2)$. Ağrıyı sonlandırma, fonksiyonel durumun arttırılması ve yaşam kalitesinin arttırılmasında total diz protezi ve kalça protezi uygulamalarının en etkili tedavi yöntemleri olduğu kanıtlanmıştır (3). Diz protezi uygulamalarında komplikasyonlar görülebilir. Bunlar kanama, yara sorunları, tromboembolik durumlar, derin eklem enfeksiyonu, periprostatik kırık, patellar tendon rüptürü, ekstensor mekanizma yaralanması, nörovasküler yaralanmalar, medial kollateral ligament yaralanması, instabilite, dizilim bozukluğu, sertlik, patellafemoral çıkık, tibiofemoral çııı, protez yüzeylerinde aşınma, osteoliz, implant gevşemesi, implant kırığı/ tibial insert çıkığı, tekrar operasyon, revizyon operasyonu ve ölümdür (4-6). Bu vaka bildiriminde amacımız diz protezi sonucu ortaya çıkabilecek çok sayıdaki komplikasyonu bildirmek ve tedavi yöntemlerini tartışmaktır.

\section{Olgu Sunumu}

Dış merkezde aynı seansta bilateral diz protezi yapılan 68 yaşındaki kadın hastada ameliyat sonrası erken dönemde sağ dizde suprakondiler femur kırığı gelişmesi üzerine hastaya açık redüksiyon ve internal fiksasyon ameliyatı yapılmış. Taburculuk sonrası tekrar travma geçiren hasta 2008 Mayıs ayında hastanemiz acil servisine başvurdu. Sağ dizde refraktür ve sol dizde insörtün çıkmasına bağı olarak diz çıkığı tespit edildi (Resim 1). Hastanın yapılan ilk muayenesinde sağ alt
Yazışma Adresi/Address for Correspondence: Özgür Korkmaz

Or-Ahayim Özel Balat Hastanesi Ortopedi ve Tavmatoloji, İstanbul, Türkiye Tel.: +90 2124910000 E-posta: ozkorkmaz00@yahoo.com

Geliş Tarihi/Received: 15 Ağustos 2012 Kabul Tarihi/Accepted: 20 Ekim 2012
The Medical Bulletin of Haseki Training and Research Hospital, published by Galenos Publishing. All rights reserved. Haseki Tıp Bülteni, Galenos Yayınevi tarafından basılmıştır. Her hakkı saklıdır. 
ekstremitede tibialis anterior motor kuvveti $3 / 5$ olarak belirlendi. Hastanın her iki diz hareketleri kısıtlıydı ve hasta mobilize olamamaktaydı. Hastaya acil olarak her iki alt ekstremiteye yönelik EMG tetkiki ve anjiyografi yapıldı. EMG'de sağ peronel sinir diz arkası bölümünde ileti hızında azalma olduğu rapor edildi. Aniyografide bir patoloji rapor edilmedi. Yapılan ameliyat öncesi planlamada suprakondiler kırık olan tarafa açık redüksiyon internal fiksasyon ameliyatı, çı kık olan tarafa da revizyon diz protezi ameliyatı planlandı. Sağ dize lateralden yapılan eski insizyondan girildi ve osteosentezde kullanılan implantlar çıkarıldı ve bu bölge anatomisine uygun olan bir anatomik plak ile greft kullanılarak osteosentez yapıldı. Sol dize anterior artrotomi ile girildi ve yapılan diz protezinde insörtün çıkmış olduğu görüldü ve diz protezi komponentlerinin tespit açılarının uygunsuz olduğu, fleksiyon ekstansiyon aralıklarının eșit olmadığı görüldü. Femur anterior kortekste yapılan kemik kesiye bağlı olarak kortikal kalınlığın azaldığı ve biyomekanik olarak anterior korteksin zayıf olduğu düşünüldü. Komponentler çıkarılarak revizyon diz protezi ameliyatı yapıldı (Resim 2). Ameliyatta arka çapraz bağı
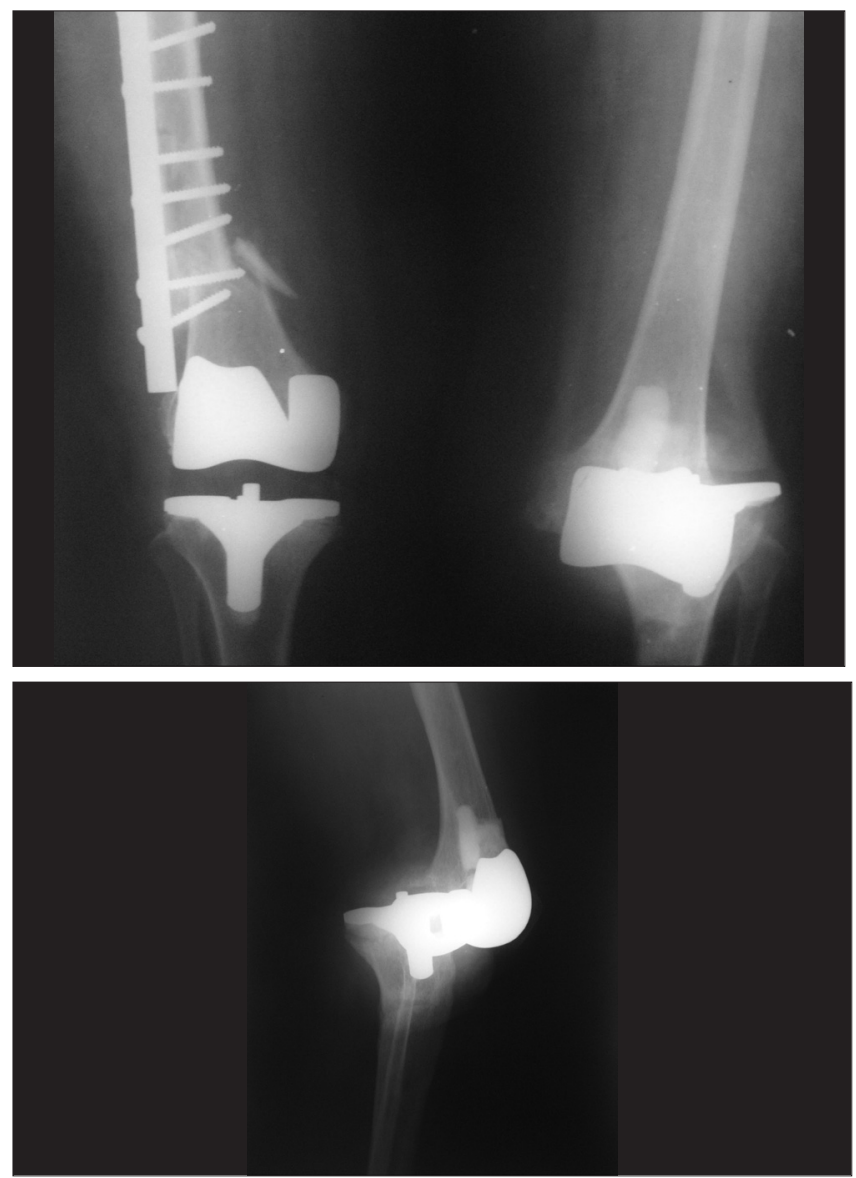

Resim 1. Preoperatif grafiler kesen sabit insörtlü revizyon diz protezi kullanıldı. Cerrahi esnasında ve sonrasında bir komplikasyon tespit edilmedi ve hasta rehabilitasyon programına alındı. Hastanın takip süresi 22 aydır. Bu takip süresi içerisinde ameliyat öncesi dönemde tespit edilen peroneal sinir patolojisinin klinik olarak geri döndüğü tespit edildi. Hastanın son kontrollerinde sağ diz fleksiyonu 95 derece ölçüldü. Sağ dizde 5 derece ekstansiyon kısıtlılı̆ı tespit edildi. Kırığın kaynadığı tespit edildi. Sol dizde fleksiyon 100 derece ölçüldü ve ekstansiyonun tam olduğu belirlendi. Her iki dizde enfeksiyon bulgusu yoktu.

\section{Tartışma}

Uygunsuz yapılan anterior distal femoral kesilerin femur korteksini zayıflatması sonucunda periprostatik kırık oluşabilir $(7,8)$. Olgumuzdaki suprakondiler periprostatik kırığa anterior femoral korteksin zayıflamasının neden olduğu düşünüldü. Suprakondiler periprostatik femur kırıklarının tedavilerinde Althausen ve ark (9) çeșitli fiksasyon metotlarını karşılaştırmışlar ve plak ile tespit
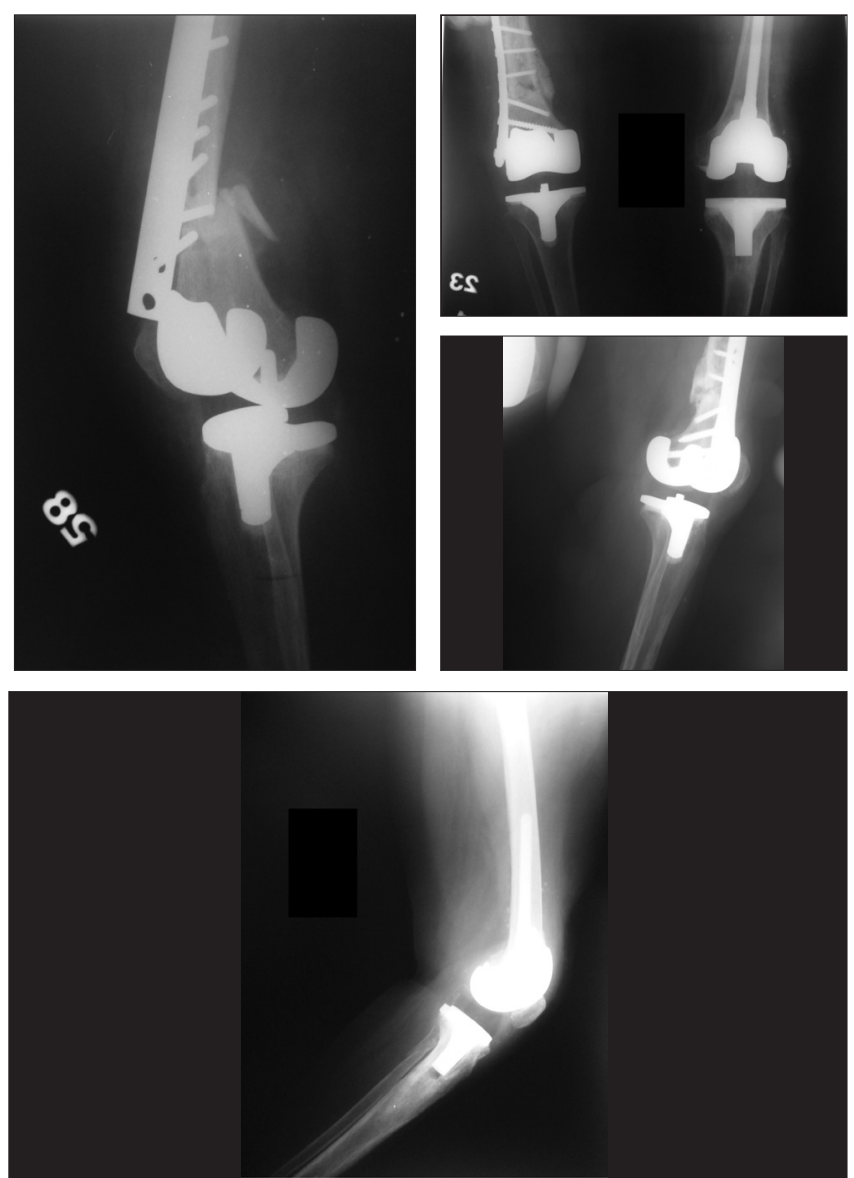

Resim 2. Postoperatif grafiler 
yönteminin daha etkili olduğunu belirtmişlerdir. Kregor ve ark (10) kilitli plak sistemleri ile yaptıkları osteosentez sonuçlarına göre femoral komponent çevresinde daha uygun bir tespit sistemi oluşturduğunu, enfeksiyon riskinin daha az olduğunu ve greft intiyacının daha az olduğunu bildirmektedirler. Biz de refraktür olan sağ dizde greft kullanarak kilitli anatomik plak kullanmayı uygun bulduk. Mihalko ve ark (11) diz protezi cerrahisinde fleksiyon ve ekstansiyon boşluklarının eşit olarak dengelenmesinin önemini vurgulamaktadır. Schuh ve ark (12), çalışmalarında hareketli sistem insört kullanılan dizlerde oluşan çıkıklar sonrası insört değişimi yerine revizyon diz protezi ameliyatı yapılmasını önermektedirler. Hagedom ve ark (13) yaptıkları çalışmada revizyon diz protezi yapılan hastalarda diz çıkığının en önemli nedeni olarak fleksiyon ve ekstansiyon aralıklarının eşit olmamasını belirtmektedirler. Villanueva ve ark (14) yaptıkları çalışmada altı diz protezi sonrası eklem çıkığı olan hastayı değerlendirmişler dört hastada fleksiyon ekstansiyon dengesizliği, bir hastada komponentlerin malrotasyonunu ve bir hastada da uygunsuz implant seçiminin neden olduğunu belirtmektedirler. Ekstansiyon ve fleksiyon açıklıklarının eşit olmaması ve komponentlerin tespit açılarının uygun olmamasının diğer dizdeki çıı̆ğın nedeni olarak düşünüldü. Biz de insört çıkığı olan sol dize arka çapraz bağı kesen sabit insörtlü revizyon diz protezi ameliyatı yaptık. Ameliyat sonrası erken dönemde komplikasyon tespit edilmemesine rağmen takip süremizin kısa olması çalışmamızı kısıtlamaktadır.

Diz protezi cerrahisi öncesi aynı seansta her iki dize protez ameliyatı yapılması planlanan hastaların dikkatli bir şekilde değerlendirilmesi gerekir. Sistemik hastalığı olan ve ileri seviyede osteoporozu olan hastalarda aynı seansta her iki dize diz protezi ameliyatı yapılmamalıdır. İnsert çıkığı ve instabilite gibi ortaya çıkabilecek komplikasyonların azaltılmasında, yumuşak doku dengesi ve kemik kesilerinin uygun yapılması çok önemlidir.

\section{Kaynaklar}

1. Badley EM, Rasooly I, Webster GK. Relative importance of musculoskeletal disorder as a cause of chronic health problems, disability and health care utilization: findings from the 1990 Ontario Health Survey. J Rheumatol 1994;21:505-14.

2. Reynolds DL, Chambers LW, Badley EM, et al. Physical disability among Canadians reporting musculoskeletal diseases. J Rheumatol 1992;19:1020-30.

3. Ethgen $\mathrm{O}$, Bruyere $\mathrm{O}$, Richy $\mathrm{F}$, et al. Health-related quality of life in total hip and total knee arthroplasty. A qualitative and systematic review of the literature. J Bone Joint Surg Am 2004;86:963-74.

4. Kaushal SP, Galante JO, McKenna R, Bachmann F. Complications following total knee replacement. Clin Orthop Relat Res 1976;121:181-7.

5. Woods GW, Lionberger DR, Tullos HS. Failed total knee arthroplasty. Revision and arthrodesis for infection and noninfectious complications. Clin Orthop Relat Res 1983;173:184-90.

6. Soohoo NF, Zingmond DS, Lieberman JR, Ko CY. Optimal timeframe for reporting short-term complication rates after total knee arthroplasty. J Arthroplasty 2006;21:705-11.

7. Lesh ML, Schneider DJ, Deol G, Davis B, Jacobs CR, Pellegrini VD $\mathrm{Jr}$. The consequences of anterior femoral notching in total knee arthroplasty. J Bone Joint Surg Am 2000;82-A(8):1096-101 .

8. Ritter MA, Thong AE, Keating EM, et al. The effect of femoral notching during total knee arthroplasty on the prevalence of postoperative femoral fractures and on clinical outcome. J Bone Joint Surg Am 2005;87:2411-4.

9. Althausen PL, Lee MA, Finkemeier CG, Meehan JP, Rodrigo JJ. Operative stabilization of supracondylar femur fractures above total knee arthroplasty: a comparison of four treatment methods. J Arthroplasty 2003;18:834-9.

10. Kregor PJ, Hughes JL, Cole PA. Fixation of distal femoral fractures above total knee arthroplasty utilizing the Less Invasive Stabilization System (L.I.S.S.). Injury 2001;32 Suppl 3:SC64-75.

11. Mihalko WM, Krackow KA. Flexion and extension gap balancing in revision total knee arthroplasty. Clin Orthop Relat Res 2006;446:121-6.

12. Schuh $A$, Hönle W. Atraumatic dislocation in mobile-bearing total knee arthroplasty: two case reports. Zentralbl Chir 2007;132:460-4.

13. Hagedorn J, Levine BR. Revision surgery for a dislocated constrained total knee arthroplasty. Orthopedics 2012;35:1099-103.

14. Villanueva M, Ríos-Luna A, Pereiro J, Fahandez-Saddi H, PérezCaballer A. Dislocation following total knee arthroplasty: A report of six cases. Indian J Orthop 2010;44:438-43. 